\title{
TRABALHO DOCENTE NA EDUCACCÃO PROFISSIONAL: DAS ESCOLAS DE APRENDIZES ARTÍFICES AOS INSTITUTOS FEDERAIS E OS DESAFIOS DO ENSINO VERTICALIZADO
}

\author{
Francislene Rosas da Silva*; Ronegildo de Souza Silva; Hellen Sandra Freires da Silva \\ Azêvedo; José Marlo Araújo de Azevedo \\ E-mail*: francislene.silva@ifac.edu.br \\ Instituto Federal de Educação de Ciência e Tecnologia do Acre
}

DOI: $10.15628 /$ rbept.2020.9769

Artigo submetido em: mar./2020 e aceito em: mar./2020

\begin{abstract}
RESUMO
A criação da Rede Federal de Educação Profissional Científica e Tecnológica em nosso país parte de inúmeras transformações históricas, educacionais, sociais desencadeando modificações na maneira de pensar e executar as políticas públicas educacionais no campo da educação profissional acarretando consequências à atividade docente. Os Institutos Federais são parte integrante dessa rede tem entre suas características a verticalização, onde os docentes se defrontam com um universo de diferentes níveis e modalidades atuando desde a educação básica a pós-graduação. Dessa forma, o estudo tem por objetivo apresentar uma evolução histórica da Educação Profissional no Brasil e os desafios enfrentados pelos docentes em sua atuação no âmbito da verticalização no Instituto Federal do Acre - Campus Cruzeiro do Sul. Os procedimentos utilizados na investigação incluíram pesquisa bibliográfica e documental e como instrumento de coleta de dados foram aplicados questionário semiestruturado. Os estudos sobre essa temática indicam que o trabalho docente no contexto verticalizado traz implicações uma vez que o docente atende a diversas áreas tanto de conhecimento quanto de níveis de ensino, fragilizando e causando a intensificação do trabalho docente.
\end{abstract}

Palavras-Chave: Verticalização. Trabalho Docente. Níveis de Ensino.

\section{TEACHING WORK IN PROFESSIONAL EDUCATION: FROM APPRENTICE ARTISAN SCHOOLS TO FEDERAL INSTITUTES AND THE CHALLENGES OF VERTICAL EDUCATION}

\begin{abstract}
The creation of the Federal network of Professional Scientific and Technological Education in our country starts from counteless historical, educational, social transformations, initiating changes in the way of thinking and executing public educational policies in the field of professional education, with consequences for teaching activities. The Federal Institutes are an integral part of this network among its characteristics is verticalization, where teachers are faced with a universe of diferente levels and modalities acting from basic education to graduate course. Thus, the study aims to present a historical development of professional education in Brazil and the challenges faced by teachers in their area under the vertical integration at the Federal Institute of Acre - Cruzeiro do Sul Campus. The procedures used in the investigation included bibliographic and documentary research and as a data collection instrument a semistructured questionnaire was applied. Studies on this theme show that teaching work in a
\end{abstract}


vertical context has implications since the teacher serves several areas, as well as knowledge about the levels of teaching, weakening and causing the intensification of teaching work.

Keywords: Verticalization. Teaching work. Education Levels.

\section{INTRODUÇÃO}

A implantação da Rede Federal de Educação Profissional e Tecnológica ocorreu num contexto de transformações históricas, econômicas, políticas de avanços e retrocessos que iniciou com as escolas de Aprendizes Artífices que culminaram com a criação dos Institutos Federais. Os Institutos Federais de Educação, Ciência e Tecnologia (IFs) foram criados pela Lei no. 11.892, em dezembro de 2008, a partir da reconfiguração das escolas federais já existentes, que reunia, à época, os Centros Federais de Educação Tecnológica (CEFETs), as Escolas Técnicas Federais (ETFs), as Escolas Agrotécnicas Federais (EAFs) e as Escolas Técnicas Vinculadas a Universidades Federais. Os IFs de cunho assistencialista, com foco na justiça social, a equidade, a competitividade econômica e a geração de novas tecnologias, visam atender às classes menos favorecidas garantindo a formação da classe trabalhadora para atender as necessidades do mercado de trabalho.

Os institutos atuam com a verticalização do ensino, onde os docentes desenvolvem ações educativas em diferentes níveis e modalidades de ensino, com uma heterogeneidade de público, compartilhando espaços pedagógicos, e diferentes itinerários formativos que vão dos cursos de formação técnica, subsequente, superior, especialização, mestrado e doutorado.

Diante disso, direcionam-se algumas preocupações que se manifestam com maior evidência ao compreender o trabalho docente no contexto verticalizado e as implicações na realização de um trabalho simultâneo no ensino, na pesquisa e na extensão em diferentes níveis e modalidades de ensino que irão refletir na educação e no trabalho docente.

O artigo tem por objetivo apresentar uma evolução histórica da Educação Profissional no Brasil e os desafios enfrentados pelos docentes em sua atuação no âmbito da verticalização no Instituto Federal do Acre - Campus Cruzeiro do Sul.

\section{METODOLOGIA}

A investigação foi realizada no Instituto Federal do Acre - Campus Cruzeiro do Sul, situado no município de Cruzeiro do Sul no interior do estado do Acre. O Campus Cruzeiro do Sul, oferta diferentes modalidades: ensino médio integrado, técnico subsequente, superior tecnológico, licenciaturas, cursos de formação inicial e continuada e cursos de pós-graduação Latu sensu.

A investigação iniciou-se com a pesquisa bibliográfica acerca da fundamentação teórica que abordam a temática da educação profissional no 
Brasil. Além disso, buscou-se verificar a verticalização e os desafios enfrentados pelos docentes que atuam nos diferentes níveis e modalidades de ensino na instituição. A pesquisa bibliográfica, ou de fontes secundárias, abrange bibliografia do tema a ser investigado desde publicações avulsas até comunicações orais. (LAKATOS; MARCONI, 2008, p. 57). Para os autores, a pesquisa bibliográfica compreende oito fases distintas, sendo elas: escolha do tema; elaboração do plano de trabalho; identificação; localização; compilação; fichamento; análise e interpretação, e pôr fim a redação.

Segundo Fonseca (2002), a pesquisa bibliográfica é feita a partir do levantamento de referências teóricas já analisadas sobre a temática em estudo, e publicadas por meios escritos e eletrônicos, como livros, artigos científicos, páginas de web sites. Ainda para o autor, qualquer trabalho científico inicia-se com uma pesquisa bibliográfica, que permite ao pesquisador conhecer o que já se estudou sobre o assunto.

Posteriormente, foi realizada a pesquisa documental na instituição, que buscou o aprofundamento do objeto de estudo e tendo por finalidade realizar um levantamento de dados nos documentos da instituição tais como: o quadro funcional dos servidores, Organização Didática Pedagógica (ODP), Plano de Desenvolvimento Institucional (PDI), Resoluções da Coordenação Técnica Pedagógica (COTEP), das Coordenações de Cursos, Histórico do Campus, Projeto Pedagógico de Curso (PPCs), Resolução da Carga Horária Docente e Funções Docentes e Documentos do Ministério da Educação (MEC) voltados para as atribuições dos docentes. A análise documental pode se constituir numa técnica valiosa de abordagem de dados qualitativos, seja completando as informações obtidas por outras técnicas, seja desvelando aspectos novos de um tema ou problema. (LÜDKE; ANDRÉ, 2007, p. 38).

Para complementar as informações sobre a verticalização no contexto dos institutos e os desafios enfrentados pelos docentes, realizou-se coletas de dados através da aplicação de questionários semiestruturado (com roteiro prédefinido, aberto e fechado), onde participaram 30 docentes que estão em efetivo exercício no Campus Cruzeiro do Sul atuando no Ensino Básico, Técnico, Tecnológico (EBTT) e licenciaturas. Visando selecionar uma amostra representativa de docentes das diferentes áreas de ensino, participaram da pesquisa docentes das áreas básicas e técnicas. Segundo Lakatos e Marconi (2010) o "questionário é um instrumento de coleta de dados, constituído por uma série ordenada de perguntas, que devem ser respondidas por escrito [...]". (LAKATOS, MARCONI, 2010, p. 184).

Quanto aos procedimentos a pesquisa se constituiu como Estudo de Caso que se configura pela possibilidade de compreensão crítica do objeto de investigação. O estudo de caso como opção metodológica se deve pela possibilidade de analisar os fatos baseados na experiência de campo, confrontando com a visão teórica das informações na realidade, com a pesquisa bibliográfica e pesquisa documental realizando a interpretação dos fatos. (GIL, 2006).

Para a realização das análises, construiu-se um banco de dados com as informações obtidas nos questionários. Posteriormente, os dados foram 
sistematizados no programa Excel for Windows $\AA^{\circledR}$. Para a confecção dos gráficos foi utilizado o programa estatístico Origin $\circledast$, versão 6.0 (Microcal Origin $\AA, 6.0$, USA). Vale ressaltar que todas as pessoas que responderam 0 questionário foram orientadas a assinar o Termo de Consentimento Livre e Esclarecido - TCLE em duas vias, uma ficando com o participante e outra com o pesquisador.

\section{RESULTADOS E DISCUSSÕES}

\subsection{CONTEXTUALIZAÇÃO HISTÓRICA DA EDUCAÇÃO PROFISSIONAL E TECNOLÓGICA NO BRASIL E A IMPLANTAÇÃO DO INSTITUTO FEDERAL DO ACRE - IFAC}

Historicamente, a educação profissional iniciou no Brasil desde 1909, a partir do decreto oㅜ 7.566/1909 com a criação de dezenove Escolas de Aprendizes Artífices no governo de Nilo Peçanha (Figura 1), onde mais tarde foram transformadas em Centro Federal de Educação Tecnológica (CEFETS), e posteriormente em Institutos Federais. Nesse período, as escolas de Aprendizes Artífices tinham como finalidade, "[...] habilitar os filhos dos desfavorecidos da fortuna com o indispensável preparo técnico e intelectual, como fazê-lo adquirir hábitos de trabalho profícuo, que os afastará da ociosidade ignorante, escola do vício e do crime". (BRASIL,1909, p.1).

Em 1937, com a expansão da industrialização no país, na qual demandaria trabalhadores qualificados, as escolas de Aprendizes Artífices tornam-se Liceus Profissionais por meio da Lei oㅡ 378/37 destinados ao ensino profissional de todos os ramos e graus sendo dever do estado sua oferta.

Na década de 1940, o Estado assume a educação profissional como modalidade de educação, tendo como foco preparar a mão de obra para o mercado de trabalho. A trajetória educacional estava definida para desempenho das funções intelectuais e a outros, as funções instrumentais. Kuenzer (2001) corrobora para o entendimento dessa concepção dual de educação quando afirma que a formação acadêmica e intelectualizada era destinada à elite, cabendo aos trabalhadores e seus filhos a formação profissional com ênfase na preparação para o exercício a um ofício. 
FIGURA 1: mapa sobre a espacialização das Escolas de Aprendizes Artífices em 1909 e respectivas datas de inauguração

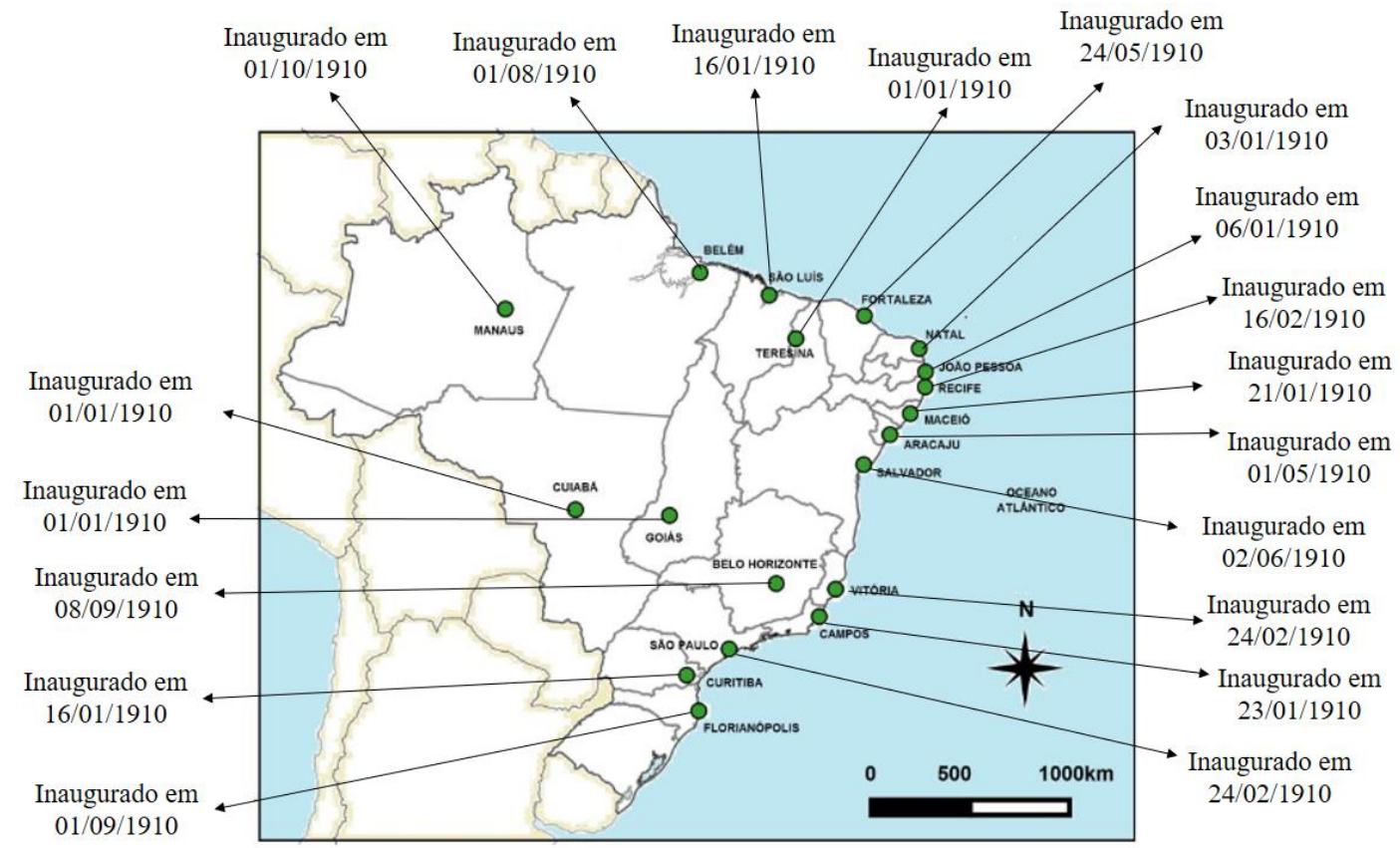

Fonte: elaborado pelos autores. Distribuição das primeiras 19 Escolas de Aprendizes Artífices. Adaptado de Silva (2017, p. 39). Garcia et al. (2018, p. 07)

Pelo decreto 4.127 de 25 de fevereiro de 1942 os Liceus Industriais são transformados em Escolas Industriais e Técnicas, passando a oferecer a formação profissional em nível equivalente do secundário.

Em 1959 as Escolas Industriais e Técnicas passaram à categoria de autarquias e foram denominadas Escolas Técnicas Federais com autonomia didática e de gestão.

Com a Lei $n .05 .692$ de 1971, o ensino profissionalizante torna-se compulsório, conferindo obrigatoriedade à habilitação profissional no ensino do $2^{\circ}$ grau. Essa busca compulsória contribuiu para conter a grande demanda por ensino superior e despolitizar o ensino secundário. Em 1982, o governo federal, por meio da Lei $n .-7.044$, extinguiu essa obrigatoriedade.

Em 1978, a partir da Lei $n^{\circ} 6.545$ se estabelece a criação das três Escolas Técnicas Federais (Minas Gerais, com sede em Belo Horizonte, Paraná, em Curitiba, e Celso Suckow da Fonseca, no Rio de Janeiro) que foram criadas para organizar e ministrar cursos de curta duração em Engenharia de Operação sendo posteriormente transformadas em Centros Federais de Educação Tecnológica - CEFETs. Esta mudança confere àquelas instituições mais uma atribuição, formar engenheiros de operação e tecnólogos, processo esse que se estende às outras instituições bem mais tarde.

No intervalo entre 1978 a 1993, ocorre a promulgação da Constituição Federal de 1988, que passa a referenciar as demais leis do país, inclusive na 
elaboração da Lei de Diretrizes e Bases da Educação Nacional no. 9.394/96, concebendo a educação profissional integrada às diferentes formas de educação, ao trabalho, à ciência, e à tecnologia, conduzindo ao permanente desenvolvimento de aptidões para a vida produtiva.

Com a promulgação da Lei oo 8.948 de 8 de dezembro 1994 institui-se - Sistema Nacional de Educação Tecnológica, transformando, gradativamente, as Escolas Técnicas Federais (ETFs) e as Escolas Agrotécnicas Federais (EAFs) em Centros Federais de Educação. A expansão da oferta da educação profissional somente ocorrerá em parceria com Estados, Municípios e Distrito Federal, setor produtivo ou organizações não governamentais, que serão responsáveis pela manutenção e gestão dos novos estabelecimentos de ensino.

Em 1997, o governo federal institui o decreto n. $-2.208 / 97$, oficializando mais uma vez a separação entre ensino médio e educação profissional e limitava os investimentos do governo na criação de novas unidades. Sendo substituído pelo decreto $n .-5.154 / 2004$, que restabelece a possibilidade de integração entre a educação básica e o ensino profissional.

Este decreto normatiza a integração do ensino técnico de nível médio ao ensino médio, estabelecendo que a educação profissional deverá ser organizada por áreas profissionais, em correspondência a cada estrutura sócio ocupacional e à base tecnológica requerida e, ainda, mediante processos articulados envolvendo as áreas de educação, trabalho, emprego, ciência e tecnologia.

A partir do decreto $5.225 / 2004$, os CEFETs foram transformados em Instituições de Nível Superior (IES) ofertando educação nos diferentes níveis e modalidades, com prioridade para atuação na área tecnológica.

Desde 2003, as políticas de governo do presidente Luiz Inácio Lula da Silva, por meio da Secretaria de Educação Profissional e Tecnológica do MEC (SETEC) já apontam para a criação de novas instituições de educação profissional que são consolidadas como as ações do Plano de Desenvolvimento da Educação (PDE) e a implementação do Plano de Expansão da Rede Federal dividida em três fases: a fase I de 2003 a 2006, a fase II iniciada em 2007 a 2010, e a fase III que se estenderá até 2020, tendo como objetivo a ampliação e a presença das instituições de ensino profissional em todo o território brasileiro. 
FIGURA 2 - Representação da linha do tempo dos 100 anos da Rede Federal de Educação Profissional e Tecnológica

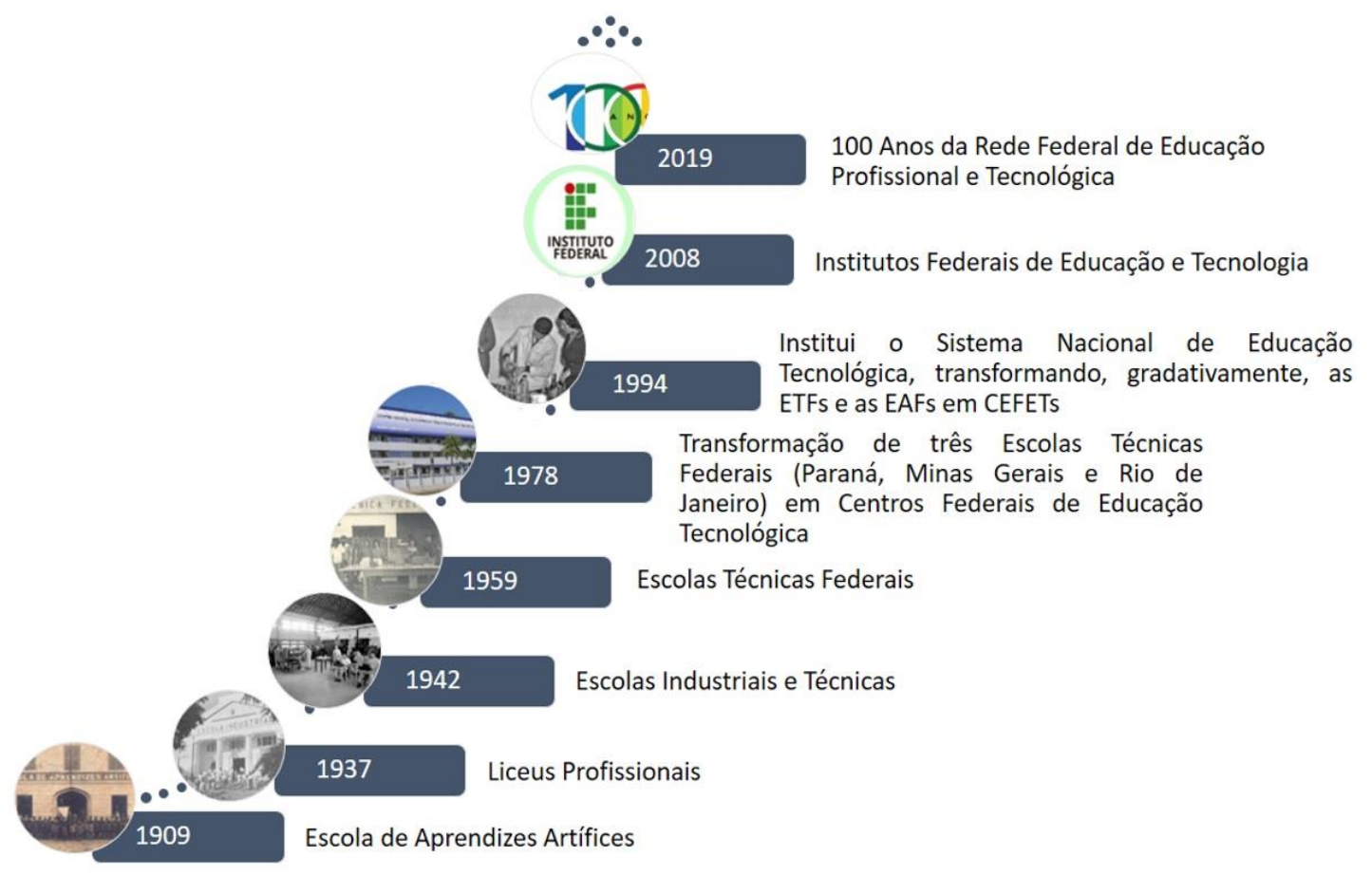

Fonte: elaborado pelos autores a partir do MEC (2020)

A Lei $n^{0}$ 11.195/2005 é considerada um marco histórico pelo fato de possibilitar, legalmente, a retomada da expansão da Rede Federal. A fase I iniciada em 2006 visava expandir a EPT chegando inclusive aos estados que não havia Rede Federal de Educação Profissional entre eles destaca-se: Os estados do Acre, Amapá, Mato Grosso do Sul e Distrito Federal. Prevendo-se a criação de cinco escolas técnicas federais e de quatro escolas agrotécnicas, bem como a implantação de 33 novas unidades de ensino descentralizadas, contemplando 23 unidades da federação com a instalação de pelo menos uma Instituição Federal de Educação Tecnológica.

$\mathrm{Na}$ fase II em 2007, a SETEC/MEC estabelece a criação em quatro anos de mais de 150 novas Instituições Federais de Educação Tecnológica. As instituições foram distribuídas nos 26 estados da Federação e do Distrito Federal, contemplando 150 municípios escolhidos pelo MEC e pelas prefeituras dos municípios.

Em 2011, inicia-se a fase III que estabelece um projeto de criação de 208 novas unidades até 2014, permanecendo o propósito de superação das desigualdades regionais e as condições de acesso a cursos de formação profissional e tecnológica para a população.

De acordo com Silva e Terra (2013) os planos de expansão visavam atender três dimensões: social, geográfica e de desenvolvimento. A dimensão social visava promover o desenvolvimento econômico atendendo a um grupo 
de 100 cidades com mais de 80 mil habitantes com baixa renda per capita e com percentual elevada de extrema pobreza e social. A dimensão geográfica visava a interiorização e universalização da Educação Profissional e Tecnológica atendendo municípios ou microrregiões com mais de 50 mil habitantes. A dimensão do desenvolvimento tinha por objetivo que os novos campi fossem em municípios com arranjos produtivos locais e que contribuíssem para o desenvolvimento social e econômico dessas localidades. Para os referidos autores essas dimensões estabelecidas pelo MEC visavam atender regiões e localidades menos favorecidas, contribuindo para minimizar os traços de desigualdades sociais.

Diante disso, o MEC/SETEC (2019) compreende que:

O resultado desse plano de expansão e interiorização das instituições federais de EPT é que a rede federal partiu em 2006, de um total de 144 unidades e chegou em 2018, a 659 unidades em todo país, dos quais 643 já se encontram em funcionamento, isto representou a construção de 500 novas unidades, quantitativo maior que o previsto nas três fases de expansão. (MEC/SETEC, 2019).

Atualmente, a Rede Federal encontra-se presente em todos os estados da federação, contribuindo com o desenvolvimento local e regional, oportunizando os jovens sua formação com bases das premissas da integração e da articulação entre a ciência, tecnologia, cultura, conhecimentos gerais, específicos e de investigação científica, tendo essas dimensões como necessárias para promoção da qualificação de cidadãos autônomos, com saberes necessários ao exercício laboral nas ações de ensino, pesquisa e extensão.

Em 29 de dezembro de 2008, após inúmeros debates, resultou-se na publicação da Lei no 11.892, que no âmbito do Ministério da Educação criou os Institutos Federais de Educação, Ciência e Tecnologia, os quais apresentam um novo modelo de Educação Profissional, estruturados a partir dos CEFETs, as escolas técnicas, agrotécnicas federais e escolas vinculadas às universidades federais.

Desse modo, é criado o Instituto Federal de Educação, Ciência e Tecnologia do Acre (IFAC), pela Lei oㅜ 11.892, de 29 de dezembro de 2008, uma instituição de educação básica profissional e superior, pluricurricular e multicampi, que possui natureza jurídica de autarquia, especializada na oferta de educação profissional e tecnológica nas diferentes modalidades e níveis de ensino.

Os Institutos Federais representam um modelo institucional de maior referência na política pública de educação profissional, pois a partir de sua implantação mudanças significativas foram vivenciadas para a melhoria da qualidade da educação no país. Tendo como base a aplicação de conhecimentos técnicos e tecnológicos em suas práticas pedagógicas. 
O Instituto Federal do Acre iniciou sua instalação no estado no ano de 2009, com o objetivo de formar e qualificar profissionais no âmbito da educação tecnológica nos diferentes níveis e modalidades de ensino, atendendo os arranjos produtivos da economia acreana e da sociedade local e regional. Inicialmente o IFAC ocupou salas cedidas pela Universidade Federal do Acre e pelo Instituto Dom Moacyr, na capital Rio Branco, e no interior, mais especificamente nos municípios de Sena Madureira e Cruzeiro do Sul, em prédios cedidos pelas prefeituras municipais e Governo do Acre.

Em meados de 2010, o IFAC iniciou seus trabalhos oferecendo cursos de Formação inicial e continuada e de formação técnica de nível médio com ênfase nos eixos tecnológicos de Recursos Naturais, Ambiente, Saúde e Segurança, Informação e Comunicação. Posteriormente, em 2011, iniciou-se a oferta dos cursos de graduação (tecnologia e licenciaturas), ampliando o número de matrículas de 400 (quatrocentas) para 1.170 (mil cento e setenta) em 2011. Vale ressaltar que o primeiro programa de pós-graduação (a nível de especialização) iniciou no ano 2014 e a primeira turma de mestrado no segundo semestre de 2018. Os diferentes níveis e modalidade de ensino que estão sendo ofertados pelo IFAC podem ser verificados na Figura 3.

FIGURA 3: Representação dos campi do Instituto Federal do Acre e os respectivos cursos que estão sendo ofertados na modalidade ensino Médio Integrado, Subsequente, Tecnológico, Licenciaturas, Bacharelado e pós-graduação

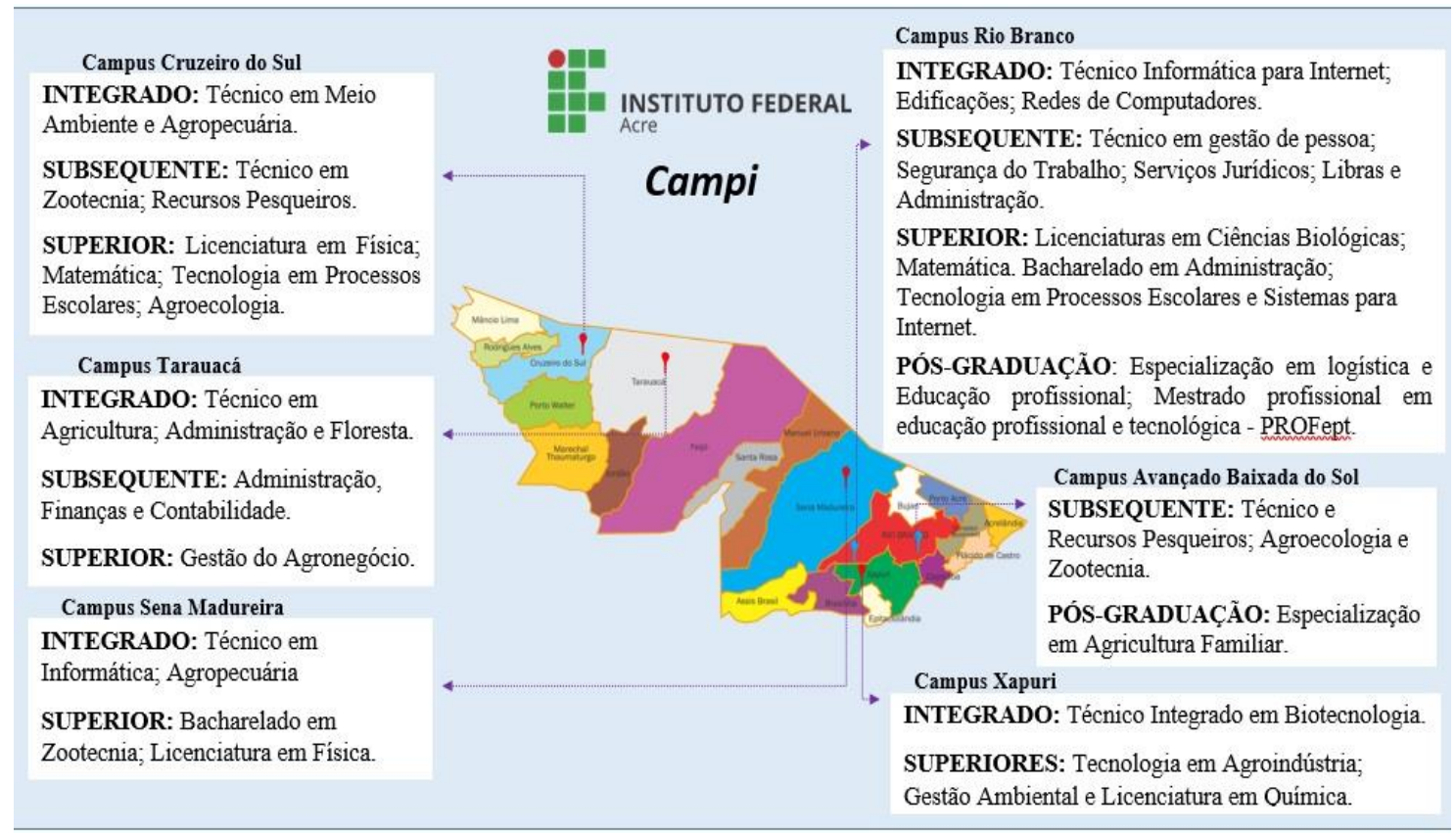

Fonte: Elaborado pelos autores (2020)

Desde 2013, o IFAC vem atuando nas 5 (cinco) microrregiões do estado do Acre, constituído por 07 (sete) unidades, sendo elas: 1) Reitoria com sede 
em Rio Branco; 2) Campus Rio Branco; 3) Campus Rio Branco Avançado Baixada do Sol; 4) Campus Xapuri; 5) Campus Sena Madureira; 6) Campus Tarauacá e 7) Campus Cruzeiro do Sul. Essas unidades ofertam vagas, em cursos técnicos: integrados e subsequentes, cursos superiores: tecnologia e licenciaturas, além dos programas especiais do governo Federal, Mulheres Mil, PRONATEC (Programa Nacional de Acesso ao Ensino Técnico e Emprego), CERTIFIC (Certificação Profissional e Formação Inicial e Continuada) e EaD (Educação a Distância), bem como a pós-graduação, propiciando a sociedade acesso a uma educação pública, gratuita e de qualidade que atende aos princípios da democratização do ensino.

Nessa perspectiva, a instituição desenvolve a formação e a qualificação de profissionais no âmbito da educação básica, técnica e tecnológica com base nos eixos de ensino, pesquisa e extensão buscando preparar os cidadãos para atuarem no mundo do trabalho como agentes de transformação social.

$\mathrm{Na}$ seção seguinte discutiremos a verticalização da Educação que representa um fator de destaque na atuação dos servidores nos Institutos Federais de Educação.

\subsection{A VERTICALIZAÇÃO DA EDUCAÇÃO NOS INSTITUTOS FEDERAIS DE EDUCAÇÃO}

Os Institutos Federais representam uma nova institucionalidade na oferta da Educação Profissional no Brasil, tendo como peculiaridade: a verticalização. A verticalização é uma característica dos IFs e tem como objetivo, de acordo com sua lei de criação, otimizar a infraestrutura física, os quadros de pessoal, os recursos de gestão, bem como integrar a Educação Básica a Superior. (BRASIL, 2008).

Nesse contexto, os Institutos Federais não são escolas técnicas e tampouco universidades, sua especificidade na institucionalidade busca promover a verticalização e a integração da educação básica à educação profissional, desenvolvendo o tripé: ensino, pesquisa e extensão, onde o mesmo corpo docente é responsável por essas ações na unidade educacional.

Esse aspecto nos IFs em oferecer diversos níveis de ensino, chamada verticalização de,

[...] diferentes níveis e modalidades da educação profissional e tecnológica, tomando para si a responsabilidade de possibilidades diversas de escolarização como forma de efetivar o seu compromisso com todos. (BRASIL, 2008, p. 27).

Dessa forma, os Institutos Federais de Educação Ciência e Tecnologia fundamentam-se na verticalização do ensino, atuam com cursos de Ensino Médio Integrado ao técnico sendo $50 \%$ das vagas, licenciaturas $20 \%$ e cursos Vol. 2 (2020) 
superiores de tecnologia e bacharelados tecnológicos $30 \%$, disponibilizando pós-graduação em nível de especialização, mestrado e doutorado.

A Educação Básica Técnica e Tecnológica exige que servidores docentes trabalhem com a verticalização. Desse modo, os docentes se deparam com uma oferta educativa diversificada e atuam nos diferentes níveis de ensino, assim o docente tem a responsabilidade e possibilidade diversa de escolarização como forma de efetivar o seu compromisso com alunos, pais e sociedade. (BRASIL, 2008).

Nesse viés, a verticalização possibilita aos discentes o conhecimento de uma diversidade de itinerários formativos que perpassa o ensino básico até 0 superior, e ocasiona modificações na ação docente, onde simultaneamente o professor irá atuar no tripé: ensino, pesquisa e extensão e nas diferentes modalidades e níveis de ensino.

Com essa diversidade de formação que vão desde os cursos de formação inicial e continuada, cursos de nível médio tais como: integrados, subsequentes, concomitantes, além da formação de nível superior de graduação e pós-graduação, os professores no contexto dos IFs se deparam em seu trabalho com essa estrutura de ensino verticalizada, além da pesquisa e da extensão. Essa proposta de ensino diversificada define as finalidades e características apresentada nos Institutos Federais de acordo com que estabelece o inciso III do Art. 6을 lei 11.892/2008 que

Os Institutos Federais têm por finalidade e características: IIIpromover a integração e a verticalização da educação básica à educação superior, otimizando a infraestrutura física, os quadros de pessoal e os recursos de gestão (BRASIL, 2008).

Diante dessa realidade os docentes que atuam nos IFs se deparam com uma oferta de ensino diversificada. Essa nova institucionalidade permite 0 compartilhamento do mesmo espaço educativo, onde os alunos do ensino médio podem conviver no mesmo espaço com os dos cursos superiores, permitindo que estes atuem coletivamente na pesquisa e na extensão, havendo dessa forma a possibilidade de ampliação nas ações educativas em diferentes contextos e itinerários formativos, e o envolvimento participativo entre a educação básica e superior.

Nesse contexto, os docentes atuarão concomitantemente no ensino, pesquisa e extensão atendendo níveis e modalidades diferentes e com públicos distintos, portanto, necessitando dos docentes uma melhor preparação didática - pedagógica e formação continuada para atuação nos referidos eixos, sendo que tal condição exigirá do professor uma ação polivalente e de flexibilidade em sua prática educativa.

Essa condição denominada de polivalência por nível de ensino acarreta implicações na ação docente, conforme afirma Cruz e Neto, 
O termo polivalência, por sua vez tem sido comumente usado no contexto do mundo do trabalho, requisitado pelo discurso neoliberal no período pós-crise do capitalismo. Designa a capacidade de o trabalhador poder atuar em diversas áreas, podendo caracterizar ainda um profissional pautado pela flexibilização funcional. Esse entendimento da polivalência tem por vezes, exercido certa influência na visão que se faz do professor/ a dos anos iniciais quando há a referência de que ele tem de cumprir múltiplas funções, aproximando-se assim de uma visão de profissional de competência multifuncional. (2012, p. 386).

Nesse sentido, o trabalho docente nos IFs se caracteriza pela diversificação, complexificação e intensificação da jornada de trabalho, o que acaba ocasionando uma sobrecarga de atribuições a serem desempenhadas pelo servidor, e a

[...] ampliação e diversificação das tarefas que os professores são chamados a desempenhar, seja, pelas mudanças na composição social do público escolar, seja pela implementação de políticas educacionais com visíveis impactos no cotidiano do trabalho em sala de aula. (LELIS ET AL., 2009, p.113).

É importante refletir sobre o papel dos docentes na carreira EBTT, pois estes, necessitam de apoio institucional para sua formação políticapedagógica, bem como conhecimento sobre a política dos Institutos Federais e sua finalidade para com a sociedade. Priorizando uma educação emancipadora que considere a importância do conhecimento técnico e tecnológico científico que permita os sujeitos compreender a totalidade social em que ele estar inserido agindo de maneira autônoma, atendendo os anseios de uma formação humana plena, omnilateral e politécnica, visando à consolidação dos eixos norteadores da educação profissional e tecnológica: cultura, ciência e trabalho.

\subsection{OS DESAFIOS DA DOCÊNCIA NO CONTEXTO DA VERTICALIZAÇÃO NO INSTITUTO FEDERAL DO ACRE/Campus CRUZEIRO DO SUL}

A institucionalidade dos IFs tendo como característica a verticalização, que possibilita ao docente que se insere nesse novo contexto a realização de ações concomitantes no ensino, pesquisa e extensão, tendo que atuar na educação básica e superior, dessa forma exigindo do profissional que seja polivalente e que tenha domínio amplo de conhecimentos abrangendo todas as áreas de atuação na instituição, bem como ser produtivo, flexível e 
adaptável as circunstâncias do meio acadêmico, buscando atender o que se preconiza na legislação.

Segundo Machado (2001) a educação profissional brasileira no âmbito dos institutos federais, evidencia amplos desafios que se abriga desde a formação inicial e continuada dos trabalhadores (incluindo a educação de jovens e adultos), a educação profissional e tecnológica de nível médio (concomitante, subsequente e integrada) e de nível superior (graduação tecnológica e pós-graduação stricto sensu de natureza profissional) que tem por finalidade a formação de cidadãos que venham contribuir com o avanço da ciência, do trabalho, da cultura e da tecnologia numa perspectiva de formação omnilateral.

Ainda segundo Machado (2019) ao trabalhar a formação docente, argumenta que os docentes da educação profissional devem ter diferentes habilidade considerando as diferentes modalidades de ensino. Afirma que:

\begin{abstract}
Para atuar na modalidade integrada, é fundamental que o professor mergulhe efetivamente nas estratégias e práticas de integração dos conhecimentos científicos, tecnológicos, sociais e humanísticos, que compõem o núcleo comum de conhecimentos gerais e universais, e os conhecimentos e habilidades relativas às atividades técnicas de trabalho e de produção. $\mathrm{Na}$ modalidade concomitante, precisa estar disponível para articular o planejamento e o desenvolvimento das suas atividades considerando o que se prevê para os cursos realizados sincronicamente pelos alunos, de modo a aproveitar as oportunidades educacionais que cada um oferece. $\mathrm{Na}$ modalidade subsequente, está desafiado a receber um alunado heterogêneo que já concluiu o ensino médio em tempos desigualados e a se empenhar para conferir a cada um dos alunos o reforço necessário da formação obtida na educação básica, paralelamente ao desenvolvimento dos conteúdos específicos ao curso técnico em questão. (MACHADO, 2019 p. 213-214).
\end{abstract}

Também é preciso ressaltar os saberes docentes inerentes as atividades desenvolvidas pelos docentes da educação profissional que atuam nos cursos superiores de tecnologia, licenciaturas e bacharelados e pósgraduação stricto sensu. Estes são desafiados a trabalhar o tripé do ensino, pesquisa e extensão articulada e contextualizada aos arranjos produtivos locais. Santos et al. (2015), ao trabalharem as tendências contemporâneos sobre a formação docente, afirmam que a pesquisa possibilita ao professor a relação com o saber já consolidado e com a reflexão que ele elabora a partir da prática e da experiência contribuindo com a elaboração do conhecimento sistemático.

Buscando compreender os desafios vivenciados pelos docentes do Instituto Federal do Acre - Campus Cruzeiro do Sul, realizamos um 
levantamento documental e aplicamos um questionário com os servidores docentes para verificarmos os principais desafios e dificuldades vivenciados em sua prática pedagógica. Verificou-se no estudo que $67 \%$ dos docentes trabalham nas diferentes modalidades de ensino, o que se faz necessário compreender os desafios e problemáticas desta atuação verticalizada.

Quando questionados sobre as dificuldades no início de sua carreira profissional no IFAC Campus Cruzeiro do Sul, $54 \%$ dos docentes responderam que tiveram dificuldades no início de sua carreira profissional, 33\% responderam que não e $13 \%$ que raramente, conforme o gráfico a seguir.

FIGURA 4: gráfico demonstrando as dificuldades no início da carreira docente no Instituto Federal do Acre, Campus Cruzeiro do Sul

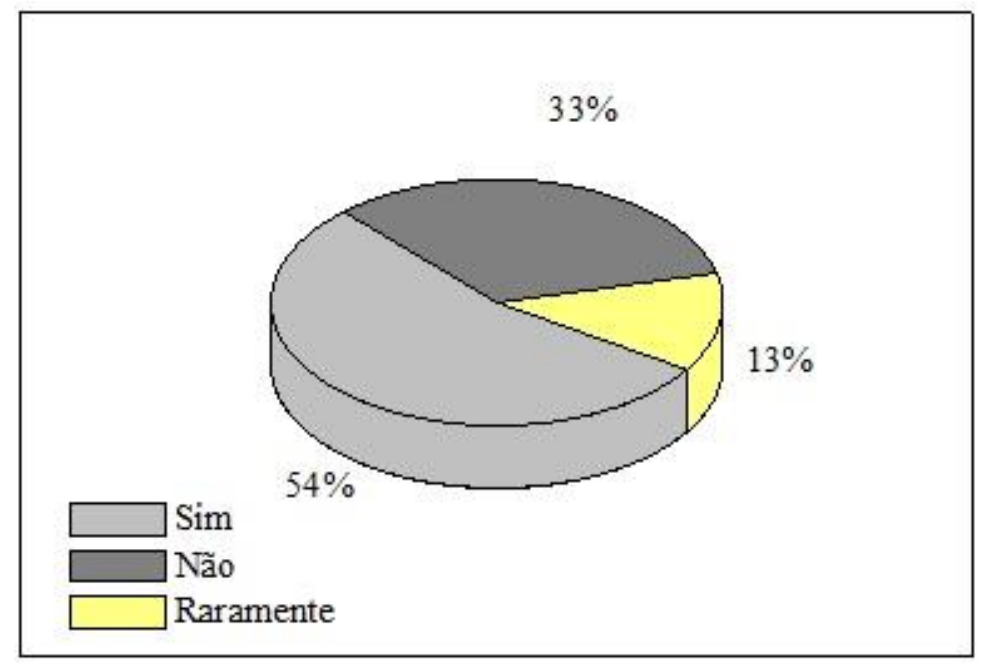

Fonte: Elaborado pelos autores (2020)

Portanto, são inúmeros os fatores que afetam o trabalho docente que causam intensificação e alongamento de sua jornada de trabalho. Como afirma Santos (2005) a questão da verticalização como característica presente nos IFs não está clara aos professores e consequentemente afeta o seu trabalho.

Estas inquietações podem ser vista na fala dos docentes ao relatar as dificuldades no início da docência.

[...] O maior desafio é ministrar aulas em todas as modalidades de ensino impactando nas ações pedagógicas, didáticas e ações educaionais... [...] dificuldade em lecionar em todos os níveis de ensino, sendo necessário uma formação específica para atuar em cada modalidade, o que não ocorreu. 
Estas dificuldades por sua vez, ocasiona impactos nas condições materias de trabalho, exigências em ações que necessitam ser desenvolvidas, bem como desafios, inquietações e dificuldades na organização do trabalho pedagógico pelo professor, que afetam sua autonomia e a materialização das atividades educacionais. Conforme afirma Lelis et al. (2009) é preciso um "[...] conjunto de condições de trabalho para uma prática que se quer competente. (LELIS ET AL., 2009, p. 10)".

Nesse cenário, é possível constatar uma quantidade de atribuições que são exercidas pelos docentes, como exemplo podemos citar: as atividades que levam para casa, planejamento de aulas, atividades burocráticas: preenchimento de diários, correção de provas, preenchimento de formulários e registros nos sistemas acadêmicos, entre outras, adicionado as atividades desenvolvidas de ensino, pesquisa e extensão, para além disso, ainda tem aqueles docentes que concomitantemente possuim cargos de representatividade na gestão da instituição que precisam conciliar com as atividades na docência.

O professor que atua na Rede Federal de Educação, é visto como um trabalhador polivalente e multifuncional tendo que enfrentar situações e problemas que vão da educação básica a superior, que afetam o seu desempenho profissional causando a intensificação de sua jornada de trabalho. Nesse sentido, é fundamental, que a instituição intensifique as ações e apoio institucional para a formação continuada de seus professores, visando à capacitação político-pedagógica nas atividades educacionais e nos eixos de ensino, pesquisa e extensão, visando à qualificação dos docentes para atuar no contexto da educação profissional e tecnológica.

Verificou-se neste estudo que ainda é necessário realizar atividades relacionadas à ação docente no IFAC, conforme as falas.

[...] tenho dificuldade em trabalhar na elaboração e diferenciar as atividades de pesquisa, atividades de extensão e projetos de ensino [...] A instituição deveria apresentar formas de trabalho e formação para atuação nos diferentes eixos. Ou ainda, [...] quando iniciei no IFAC tiver que sair perguntando a um ou outro, os procedimentos institucionais, para cumprir com todas as demandas solicitadas [...] desconhecimento sobre os documentos institucionais.

Verificou-se que outra dificuldade enfrentada pelos docentes que ingressam na Rede Federal é de trabalhar no tripé ensino, pesquisa e extensão. Observou-se que entre os docentes que atuam no Campus Cruzeiro do Sul, $43 \%$ afirmaram terem sido orientados a trabalhar com os referidos eixos, $17 \%$ responderam que não, 37\% que em parte e 3\% não responderam, conforme o Gráfico 2. 
FIGURA 5: Gráfico sobre os servidores docentes que receberam orientação para atuar no tripé ensino, pesquisa e extensão no Instituto Federal do Acre, Campus Cruzeiro do Sul

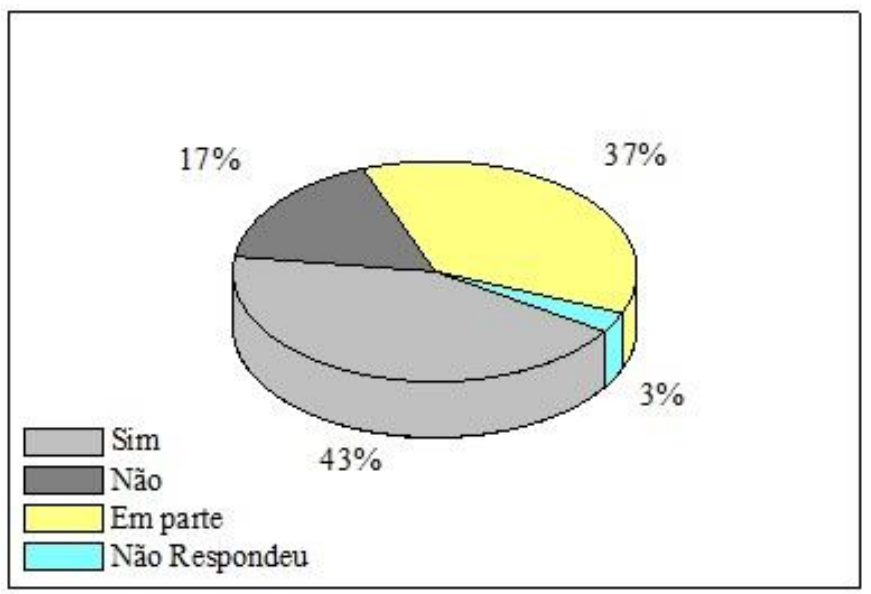

Fonte: elaborado pelos autores (2020)

De acordo com os dados coletados um número significativo de docentes afirma terem sido orientados sobre os eixos de pesquisa e extensão. Isso se justifica pelo fato de que grande parte do corpo docente que atua na EPTT no Campus Cruzeiro do Sul possui diferentes formações, dos docentes que participaram da pesquisa, 2 são graduados, 9 são especialistas, 10 mestres, 6 mestrandos, 2 doutores e 1 doutorando. Portanto, grande parte desses profissionais possui qualificação de mestrado ou estar em andamento em diversas áreas de conhecimento o que facilita a compreensão e a aptidão na execução das atividades com os eixos de pesquisa e extensão.

Vale salientar que dos docentes que participaram da pesquisa $76,7 \%$ atuam nas áreas de conhecimento geral, sendo licenciados e, portanto, possuem formação pedagógica, relatando possuir experiência na docência, tendo, como base o conhecimento de conteúdo específico e a prática pedagógica. Verificou-se ainda que $23,3 \%$ são docentes de áreas técnicas, com formação superior em bacharelado, possuem pouca ou nenhuma referência pedagógica, entretanto, maior habilidade com a pesquisa e a extensão. Essa diversidade de formação pode ser usada para potencializar as ações da instituição por meio da troca de experiência entre os servidores, porém essa política ainda não é consolidada no Campus Cruzeiro do Sul, conforme relatado.

[...] A interação com profissionais da área é muito importante para a troca de ideias e sucesso dos alunos. Ou ainda. [...] houve troca de experiência somente com um professor, que se mostrou receptivo para me auxiliar. Não fui informada sobre o público alvo e não houve a troca de experiências direcionadas pela instituição. Como o planejamento coletivo. 
Salienta-se, que o papel dos docentes que atuam nos Institutos Federais é contribuir de forma significativa com a redução das desigualdades sociais e regionais por meio da relação entre ensino, pesquisa e extensão, além de possibilitar o diálogo entre as esferas governamentais, contribuindo com as potencialidades regionais e os arranjos produtivos locais. Portanto, a atuação docente se apresenta como desafiadora no contexto dos institutos federais, pois, faz-se necessária a articulação dos saberes científicos e tecnológicos que possa romper com a dualidade educacional buscando o trabalho como princípio educativo, superando a dicotomia do trabalho manual e intelectual, onde a educação esteja voltada para a formação integral, cientifica, tecnológica, cultural e social

[...] O fazer pedagógico desses Institutos, ao trabalhar na superação ciência/tecnologia e teoria/prática, na pesquisa como princípio educativo e científico, nas ações de extensão como forma de diálogo permanente com a sociedade revela sua decisão de romper com um formato consagrado por séculos, de lidar com o conhecimento de forma fragmentada. (MEC/SETEC, 2008, p. 32).

Os Institutos Federais, em sua concepção, na busca de soluções para os problemas de seu tempo, mesclam trabalho, ciência, tecnologia e cultura, aspectos que precisam estar articulados ao dinamismo histórico da sociedade em seu processo de desenvolvimento. (SILVA; TERRA, 2013; MEC/SETEC, 2008, p. 34).

Os eixos trabalho, ciência, tecnologia e cultura serão fortalecidos mediante os vínculos dos institutos e sua integração com a comunidade interna e externa, compreendendo o seu papel para a formação humana integral em que as ações de ensino, pesquisa e extensão desenvolvidas sejam de fato pautadas no compromisso ético, político, de transformação da realidade na qual a instituição estar inserida.

Partido desse pressuposto é possível verificar que o docente do Campus Cruzeiro do Sul tem avançado na formação acadêmica de qualidade em nível de especialização, mestrado e doutorado. Estes precisam no momento de apoio institucional para sua formação alinhada com a política educacional dos institutos federais e sua finalidade para com a sociedade contribuindo com os arranjos produtivos locais.

Necessitam também de formação didático-pedagógica que Ihes propiciem conhecimentos e saberes relativos aos processos de ensinoaprendizagem que os tornem ainda mais qualificados para o exercício da docência nos diferentes níveis e modalidades de ensino favorecendo assim o trabalho na perspectiva da verticalização.

Entretanto, a formação continuada ofertada aos docentes da rede federal deve ser um processo de aperfeiçoamento e aprimoramento dos saberes inerentes a sua atividade profissional. Para isso, faz-se necessária 
uma política permanente e ampla de formação e capacitação, buscando qualificar os docentes no campo didático-pedagógico para melhor enfrentarem os desafios da educação profissional e do ensino verticalizado.

No gráfico da Figura 6 é possível observar a percentagem de servidores que participaram de formação no Campus Cruzeiro do Sul.

FIGURA 6: Percentagem de docentes que participaram de Formação pedagógica continuada no Instituto Federal do Acre, Campus Cruzeiro do Sul.

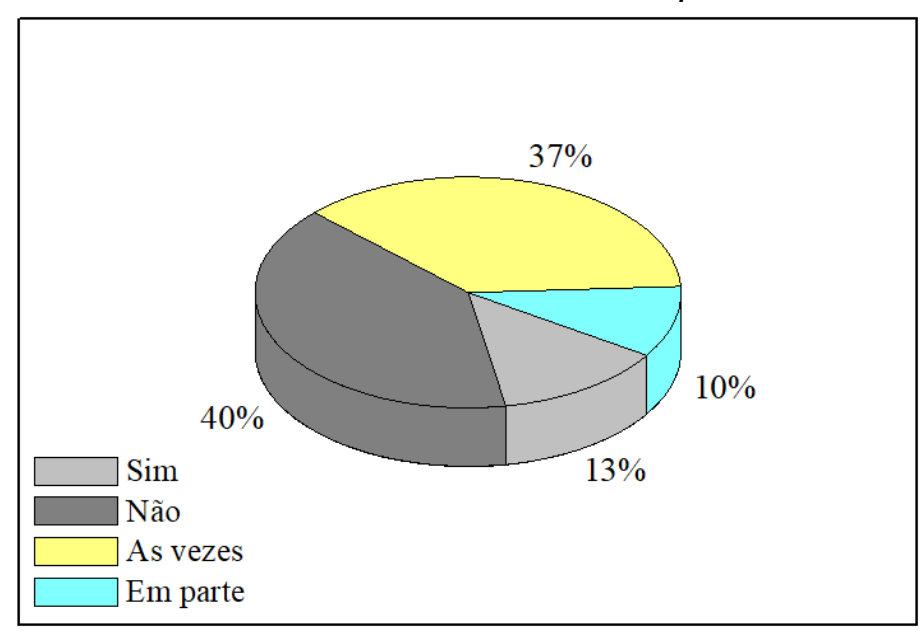

Fonte: elaborado pelos autores (2020)

Observou-se que $40 \%$ dos docentes que participaram da pesquisa afirmaram não ter recebido formação por parte da instituição. Entretanto, esta demanda é uma necessidade que se verifica na fala dos docentes.

[...] as principais dificuldades que encontro no meu trabalho é a falta de formação pedagógica que possa auxiliar nas atividades diárias. Ou ainda, [...] uma das dificuldades que encontro é a falta de acompanhamento e orientação adequada de como proceder em determinadas situações. Também foi relatado [...] semana pedagógica é fundamental [...] na minha opinião deve ser realizado capacitação dos servidores nas diferentes áreas de atuação. $\mathrm{E}$ ainda [...] tenho necessidade de formação para atuar nas diferentes modalidades de ensino, isso é fundamental para os processos de ensino aprendizagem.

Para Silva (2017), ao estudar a verticalização do ensino no Instituto Federal do Triângulo Mineiro - IFTM no Campus Uberlândia argumenta que é notório, que são raros os momentos de formação continuada e de atividades de atualização ao corpo docente na instituição, devido a inúmeras atribuições 
inerentes a sua função o que muitas vezes dificulta sua participação nos processos formativos.

Nesse sentido, os dados coletados inferem em uma realidade educacional em que no âmbito institucional inexistem ações pedagógicas voltada para a discussão de temas relacionados ao desenvolvimento dos cursos, sua organização e a atuação profissional no contexto da verticalização.

Ressaltamos a importância da formação continuada em que os professores possam refletir criticamente sobre sua prática, buscando atender suas especificidades, visando dotar esse profissional de conhecimentos científicos, culturais, pedagógicos e pessoais, para que este possa assumir a tarefa educativa em toda sua complexidade. A esse respeito, partilhamos a ideia de Alarcão e Veiga (1998) de que,

[...] O conhecimento do professor não é meramente acadêmico, racional, feito de factos, noções e teoria, como também não é um conhecimento feito só de experiência. É um saber que consiste em gerir informação disponível e adequá-la estrategicamente no contexto da situação formativa [...]. É um saber agir em situação. (ALARCÃO; VEIGA, 1998, p.104).

Por isso, torna-se, cada vez mais importante pensar a formação do professor como pesquisador, uma vez que, segundo Freire (1996) "não há ensino sem pesquisa e pesquisa sem ensino", pois, para ensinar é preciso que o professor esteja num permanente buscar, investigar, pesquisar, indagando acerca dos resultados do processo decorrente de sua prática pedagógica diária.

Portanto, essas ações de formação pedagógica para a construção da identidade profissional do professor, devem ser proporcionadas pela instituição a fim de garantir a conquista complementar, a mudança e a melhoria da formação inicial, oportunizando aos professores a superação dos desafios rumo à formação de alunos cada vez mais autônomos, críticos, solidários e democráticos.

\section{CONSIDERAÇÕES FINAIS}

Pelos resultados apresentados evidencia-se a complexidade da organização do trabalho docente nos IFs com a verticalização do ensino que ocasiona a intensificação, e um desafio da formação continuada para o trabalho docente.

Desse modo, pode-se argumentar que muitos docentes ainda não estão preparados para atuarem no contexto da verticalização. No âmbito da educação profissional o professor precisa constantemente se atualizar e se informar, não somente em relação ao mundo que o cerca, mas, principalmente, 
em relação aos saberes pedagógicos, curriculares e às inovações educacionais, buscando atender as especificidades e as múltiplas tarefas inerentes a sua profissão.

No contexto da verticalização, muitos fatores influenciam o exercício da docência nos institutos federais, sendo que os professores da EBTT ingressam na carreira através de concurso público com uma formação inicial básica que muitas vezes não contempla todo o conhecimento e saberes necessários para o exercício da docência, da pesquisa e extensão e nas atividades em cargos de gestão educacional. Os impactos da verticalização no trabalho dos professores refletem no processo educativo, causando tensões e exigências sobre suas atividades e desafios que são caracterizados por várias atribuições e responsabilidades nas diferentes dimensões institucionais e de organização do trabalho pedagógico.

Portanto, nota-se que a formação inicial não contempla o conjunto de necessidades que a profissão exige, devido a sua enorme complexidade, sendo necessário maior respaldo pedagógico, pois são escassas as formações existentes nas instituições capazes de atender e dar subsídios para a atuação do profissional da educação básica, técnica e tecnológica.

Um dos desafios em trabalhar nos institutos federais refere-se ao trabalho do docente em atuar em níveis diferentes com aplicação de métodos, adequação de conteúdo, linguagens, procedimentos, planejamento, com uma heterogeneidade de público, percorrendo simultaneamente vários níveis de ensino. Nesse sentido, é necessário adequar a linguagem e a densidade de conteúdos ao público. A adequação dos conteúdos e linguagens não é tarefa fácil, é por isso que a verticalização ainda representa um grande desafio.

Nesse sentido, faz-se necessário uma nova postura tanto por parte dos governos como da própria gestão institucional em mudar, romper com velhos paradigmas, respondendo às demandas da atualidade e proporcionando aos profissionais da docência sua preparação para essa nova forma de atuação, por meio de formações continuadas permanentes, qualificando pedagogicamente os professores para desempenharem suas atividades, seja no ensino médio integrado, subsequente, ou nos cursos superiores, tecnológicos, licenciaturas e bacharelado, assim como nos programas de pósgraduação, de acordo com seus interesses e necessidades. Permitindo a construção de um profissional docente reflexivo e criativo capaz de desenvolver uma transposição didática contextualizada que permita os avanços significativos nos processos educativos e na construção da autonomia dos educandos.

\title{
REFERÊNCIAS
}

\author{
ALARCÃO, I.; VEIGA, I. P. A. Formação continuada como instrumento de \\ profissionalização docente. Caminhos da profissionalização do \\ magistério. campinas: Papirus, 1998.
}


BRASIL, Decreto 7.566 de 23 de setembro 1909. Créa nas capitais dos Estados da Republica Escola de Aprendizes e Artífices, para o ensino profissional primário e gratuito. Diário Oficial da União: seção 1. Rio de Janeiro, RJ, 26 set.1909, p.6975.

BRASIL, Lei N 378 de 13 de janeiro de 1937. Dá nova organização ao Ministério da Educação e Saúde Pública. Diário Oficial da União: coluna 1. Rio de Janeiro, RJ, 15 jan.1937, p.1210.

BRASIL, Decreto 4.127 de 25 de fevereiro de 1942. Estabelece as bases de organização da rede federal de estabelecimentos de ensino industrial. Diário Oficial da União: seção 1. Rio Janeiro, RJ, 27 de fev. 1942, p.2957.

BRASIL, Lei $\mathbf{N}^{\circ} \mathbf{5 . 6 9 2}$ de 11 de agosto de 1971. Fixa Diretrizes e Bases para o ensino de $1^{\circ}$ e $2^{\circ}$ graus, e dá outras providências. Diário Oficial da União: seção 1. Brasília, DF, 12 de ago. 1971, p.6377.

BRASIL, Lei № 6.545 de 30 de junho de 1978. Dispõe sobre a transformação das Escolas Técnicas Federais de Minas Gerais, do Paraná e Celso Suckow da Fonseca em Centros Federais de Educação Tecnológica e dá outras providências. Diário Oficial da União: seção 1. Brasília, DF, 30 de jun.1978, p. 1.

BRASIL, Lei $\mathbf{N}^{\circ} \mathbf{7 . 0 4 4}$ de 18 de outubro de 1982. Altera dispositivos da Lei no 5.692, de 11 de agosto de 1971, referentes à profissionalização do ensino de $2^{\circ}$ grau. Diário Oficial da União: seção 1. Brasília, DF, 19 de out. 1982, p.19539.

BRASIL, Lei № 8.948 de 8 de dezembro de 1994. Dispõe sobre a instituição do Sistema Nacional de Educação Tecnológica e dá outras providências. Diário Oficial da União: seção 1. Brasília, DF, 09 de dez. 1994, p.18882.

BRASIL, Lei N 9394 de 20 de dezembro de 1996. Estabelece as diretrizes e bases da educação nacional. Diário Oficial da União. Brasília, DF, 23 de dez. 1996, p.1-27.

BRASIL, Decreto $N^{\circ} 2.208$ de 17 de abril de 1997. Regulamenta o $\S 2^{\circ}$ do art. 36 e os arts. 39 a 42 da Lei no 9.394, de 20 de dezembro de 1996, que estabelece as diretrizes e bases da educação nacional. Diário Oficial da União: seção 1. Brasília, DF, 18 de abr. 1997, p.2579.

BRASIL, Decreto $\mathbf{N}^{\circ} \mathbf{5 . 2 2 5}$ de 1 de outubro de 2004. Altera dispositivos do Decreto no 3.860, de 9 de julho de 2001, que dispõe sobre a organização do ensino superior e a avaliação de cursos e instituições, e dá outras providências. Diário Oficial da União: seção 1. Brasília, DF, 04 de out. 2004, p.5.

BRASIL, Lei № 5.154 de 23 de julho de 2004. Regulamenta $\circ \S 2^{\circ}$ do art. 36 e os arts. 39 a 41 da Lei n 9.394, de 20 de dezembro de 1996, que 
estabelece as diretrizes e bases da educação nacional, e dá outras providências. Diário Oficial da União. Brasília, DF, 23 de jul. 2004, p.1-3.

BRASIL, Lei $\mathbf{N}^{\circ} \mathbf{1 1 . 1 9 5}$ de 18 de novembro de 2005. Dá nova redação ao $\S$ $5^{\circ}$ do art. $3^{\circ}$ da Lei no 8.948 , de 8 de dezembro de 1994. Diário Oficial da União. Brasília, DF, 18 de nov. 2005, p.91.

BRASIL, Lei no 11.892, de 29 de dezembro de 2008. Cria os Institutos Federais de Educação Ciência e Tecnologia.

Disponível:<emhttp://www.planalto.gov.br/civil_03 /_ato20072010/2008/lei/l11892.htm>. Acesso em 07 nov.2018.

CRUZ, S. P. da S.; BATISTA NETO, J. A. polivalência no contexto da docência nos anos iniciais da escolarização básica: refletindo sobre experiências da pesquisa. Revista Brasileira de Educação, v.1, n. 50, p. 385-499, 2012. FREIRE, P. Pedagogia da Autonomia: saberes necessários à prática educativa. São Paulo: Paz e Terra, 1996.

GARCIA, A. de C.; DORSA, A. C.; OLIVEIRA, E. M. de. A educação profissional no Brasil: origem e trajetória. Revista Vozes dos Vales, p.1-18, 2018.

GIL, A. C. Como elaborar projetos de pesquisa. 4.ed. São Paulo: Atlas, 2006.

HUBER-RODRIGUEZ, B. Origin 9.1: A review». Physics Today. ISSN 00319228. doi:10.1063/PT.5.9008 «Review article in Scientific Computing (OriginPro 8)». Consultado em 16 de junho de 2010. Arquivado do original em 15 de fevereiro de 2012.

KUENZER, A. Ensino médio e profissional: as políticas do estado neoliberal. 3. ed. São Paulo: Cortez, 2001.

LAKATOS, E. M.; MARCONI, M. A. Fundamentos de Metodologia

Científica: técnicas de pesquisa. 7 ed. São Paulo: Atlas, 2010.

LAKATOS, E. M.; MARCONI, M. A. Técnicas de pesquisa. 3. ed. São Paulo: Atlas, 2008.

FONSECA, J. J. S. Metodologia da pesquisa científica. Fortaleza: UEC, 2002.

LELIS, I.; IÓRIO, Â. C. F.; MESQUITA, S. S. A.; NASCIMENTO, M. das G. O trabalho docente: a tensão entre intensificação e bem-estar - profissional. In: LELIS, I.; NASCIMENTO, M. das G. (Org). O trabalho docente no Século XXI quais perspectivas?. Rio de Janeiro: Forma \& Ação, 2009.

LELIS, I. A. O. M.; NASCIMENTO, M. G.; M, S. O ofício de professora em escolas de alto desempenho no Rio de Janeiro. In: 32 reunião anual da Anped, 2009, caxambu. Sociedade, cultura e educação: novas regulações?. Recife: Espaço Livre- Timbaúba, 2009. p. 1-17. 
LÜDKE, M.; ANDRÉ, M. E. D. Pesquisa em Educação: abordagens qualitativas. 10.ed. São Paulo: E.P.U, 2007.

MACHADO, L. R. S. Formação Docente para a Educação Profissional: limites e possibilidades de institucionalização. Belo Horizonte, MG. Cadernos de Pesquisas, v. 26, n. 4, 2019.

MACHADO, L. R. S. O desafio da formação de professores para a EPT e Proeja. Educação \& Sociedade, campinas, São Paulo, v. 32, n. 116, p. 689704, jul./dez. 2011.

MEC/SETEC (2019). Expansão da Rede Federal. Disponível em: $<$ http://portal.mec.gov.br/setec-programas-e-acoes/expansao-da-redefederal>. Acesso em 21 de maio de 2019.

MEC, Portal do Ministério da Educação. Linha do Tempo Rede Federal de Educação Profissional Tecnológica. Disponível http://portal.mec.gov.br/setec/arquivos/centenario/linha.pdf , Brasília - DF, 2020.

SANTOS, M. do. C. dos. Sob a égide do conflito: a reforma da educação profissional no CEFET-BA. 2005, 251 f. Tese (Doutorado) - Universidade Federal da Bahia, Salvador, 2005.

SANTOS, A. de S.; AZEVEDO, R. O. M.; GONZAGA, A. M. Tendências dos Saberes na formação profissional do professor: um olhar a partir do ensino tecnológico. Manaus, AM. Revista de Estudos e Pesquisas sobre Ensino Tecnológico - EDUCITEC, v. 1, n. 2, 2015.

SETEC/MEC. Um novo modelo em Educação Profissional e Tecnológica: Concepções e Diretrizes. Brasília, DF, Ministério da Educação, 2010, p.1-44.

SILVA, A. R.; TERRA, D. C. T. A expansão dos Institutos Federais de Educação, Ciência e Tecnologia e os desafios na contribuição para o desenvolvimento local e regional. In: I Seminário Nacional de Planejamento e Desenvolvimento, Curitiba, 2013.

SILVA, J. G. da. A expansão da rede federal de educação profissional, científica e tecnológica entre os anos 2005 e 2015 e suas implicações socioespaciais no estado de santa catarina. 2017. Tese (Doutorado e Geografia) - Programa de Pós-Graduação em Geografia da Universidade Federal de Santa Catarina. Florianópolis - SC. 2017.

SILVA, D.C. A verticalização do Ensino nos Institutos Federais: uma abordagem a partir da percepção do trabalho docente no IFTM. 2017. (Dissertação de mestrado) Programa de Mestrado em Estudos Profissionais Especializados em Educação: Especialização em Administração das Organizações Educativas. Instituto Federal do Triangulo Mineiro. Minas Gerais-MG. 2017. 